\section{PROJECT REACH}

- Approximately 12,000 community members (including teachers, sporting coaches and parents) have received some level of training in suicide risk factors and warning signs since the beginning of the project;

- More than 500 nurses have received training in suicide assessment;

- Calls from young people in the Greater Murray Area to the Kids Help Line have increased dramatically since active promotion began in March 1998. An average of 39 young people from the Greater Murray ring the Kids Help Line each day, compared to an average of 12 calls per day prior to the project;

- The Make A Noise youth health Web site has been visited by more than 60,000 people since its launch in mid-1998. 㱐

For further information about the project, or to obtain a copy of the Make A Noise: Preventing Suicide Through Community Development Interim Report 1997-98, contact the Greater Murray Health Promotion Business Unit on (02) 60581700.

\title{
SAFETY-FIRST IN RYDE
}

Mary Psaromatis and Pete Whitecross

Northern Sydney Area Health Service

The Safe Communities approach to safety promotion has been part of a World Health Organization (WHO) initiative to reduce injury since the mid-1980s. It is based on the experience of communities like Falkoping, Sweden, where it was found that community-based safety promotion reduced injury rates by 27 per cent over three years. ${ }^{1}$ The first WHO accredited Safe Communities projects in Australia were the Illawarra and Hume City (1994), followed by Noarlunga, La Trobe and Parkes (1996). This report provides a description of the Safe Communities process undertaken in Ryde NSW that, along with similar processes in Manly, Warringah, Pittwater and Mosman, was accredited by WHO earlier this year. The report examines the structure of the project and provides a commentary on the intersectoral partnerships that have supported the process.

The city of Ryde falls within the Northern Sydney Area Health Service (NSAHS). In the NSAHS, injury accounts for nine per cent of all hospital admissions for males and six per cent for females, with about 14,000 injury-related admissions annually. ${ }^{2}$ For the 1995-96 financial year, there were 2,014 injury-related hospital separations involving residents of Ryde (estimated population 96,429 in 1996). The NSAHS selected the WHO Safe Communities approach to address this injury problem.

\section{PROJECT STRUCTURE}

The Safety-First in Ryde project is a partnership of local organisations and community members whose purpose is to address known hazards and community concerns about safety in the city of Ryde. Like other Safe Communities projects, the Ryde project has a steering committee and a number of working groups, each of which addresses a specific safety issue. The working groups reflect the current priorities in Ryde, which are:

- community safety

- pedestrian safety

- falls prevention

- child safety.

These priorities were selected after extensive community consultation and analysis of available data.

Steering committee members represent Ryde City Council, the local police, the Northern Sydney Area Health Service, the NSW Department of Education and Training, the local divisions of general practice, a local member of Parliament, service clubs and community organisations. As a result of this wide representation, a variety of resources have been mobilised to support the project and a broad range of networks have been accessed. While the different groups have different priorities, there is now a greater degree of collaboration, with benefits for all stakeholders in terms of funding, staff, credibility, equipment and premises. Further, sharing responsibilities and ideas has led to some innovative initiatives. For example, the Community Safety Working Group has carried out 
community-wide safety surveys and lobbied Standards Australia to make changes to building standards.

\section{EVALUATING PARTNERSHIPS}

In any partnership that involves a variety of agencies and individuals, it is necessary to manage the development of relationships carefully. The dynamics of the emerging partnership were the focus of an evaluation study conducted by the Department of Public Health and Community Medicine at the University of Sydney. ${ }^{3}$

The aims of the evaluation were to assess the degree to which the project had:

- established a viable safety network

- developed partnership capacity to promote safety

- influenced policies and structures

- established mechanisms for community involvement.

The study was conducted using an instrument developed for assessing the strength of coalitions. ${ }^{4}$ Some of the strengths highlighted by the study were:

- a high level of agency commitment

- a good range of community participation

- an increased capacity of participating organisations to undertake safety promotion initiatives

- new networks as a result of the project.

The evaluation also highlighted issues requiring attention:

- clarifying what type of coalition it wants to be

- clarifying the roles of the steering committee and working groups

- defining the roles and responsibilities of the coordinator and member organisations.

The process of providing feedback on the report served to focus the thinking of the steering committee. Since the WHO accreditation, the steering committee has moved to clarify its role and to take a more proactive appraoch, as opposed to being a loose alliance of interested parties.
Pressures to maintain the project's sustainability have made the participants work together more closely. Despite being only two years in the making, the Safety-First in Ryde project has addressed these challenges constructively and has now created a more ambitious strategic direction. In addition, the partners now have a stronger commitment to the issue of safety promotion.

In its initial stages, the project was quite dependent on the project officer who supported all the committees and moderated the impact of the cultural variability of the participating agencies and individuals. Through the results of the evaluation, the various committees and groups recognised the vulnerability of this situation and are now continuing to operate productively without a project officer.

\section{CONCLUSION}

The goal of enabling a local community to take more responsibility for safety cannot be transplanted easily from one community to another. In working within the Safe Communities framework, participants have realised that, while much can be learned from the experiences of other communities, it is not possible to simply apply others' solutions without understanding the local situation.

\section{REFERENCES}

1. Svanstrom L, Schelp L, Ekman R, Lindstrom A. Falkoping, Sweden, ten years after: Still a safe community? International Journal for Consumer Safety 1996; 3(1): 1-7.

2. Staff M, Skinner J, Brnabic A, Holt D, March L. Health from the Harbour to the Hawkesbury: Injury Update 1996. Sydney: Northern Sydney Area Health Service, 1997. ISSN 1037 3101.

3. Sefton C, Hawe P. Evaluation of Ryde Safe Communities Project. Sydney: Department of Public Health and Community Medicine, University of Sydney, 1999. Unpublished.

4. Hawe P, Noort M, King L, Jordens C, Lloyd B. Indicators to help with building capacity to promote health. Sydney: Health Promotion Strategies Unit, NSW Department of Health. 1999. Unpublished. 